\title{
Knowing when to stop: inhaled corticosteroids and COPD
}

\author{
Peter Calverley
}

Affiliation: Institute of Ageing and Chronic Disease, University of Liverpool, Liverpool, UK.

Correspondence: Peter Calverley, Clinical Science Centre, University Hospital Aintree, Longmoor Lane, Liverpool, L9 7AL, UK. E-mail: pmacalaliverpool.ac.uk

0 @ERSpublications

Inhaled corticosteroids may help some patients with COPD, but we need to better define who those patients might be http://ow.ly/RZGSh

The past decade has seen enormous efforts to identify better treatments for chronic obstructive pulmonary disease (COPD) and progress has been made [1,2]. Despite this work controversies remain about which treatment to choose. Nowhere is this uncertainty more evident than in the use of inhaled corticosteroids (ICS). Most regulatory agencies and guidelines accept that ICS reduce exacerbations and improve health status and that combining ICS and long-acting beta-agonist (LABA) drugs produces larger changes in lung function and greater clinical benefits than either alone [3]. The large TORCH trial failed to conclusively show a difference in mortality between ICS-LABA treatment and placebo [4], although more recent database studies suggest that such an effect may be present in a "real-world" population of older patients [5]. Despite this evidence for efficacy some observers remain sceptical, raising doubts about the conduct and interpretation of the large clinical trials that have evaluated these drugs [6]. With hindsight a number of potential weaknesses have been identified but thus far no systematic bias has been shown to invalidate the primary results of these studies. The critics of ICS use fail to recognise that the perfect is the enemy of the possible when recruiting patients to clinical studies. A particular problem for COPD trialists has been the widespread use of the drug class under study which means that active treatment has been discontinued in order to allow randomisation to a study. As this therapy was likely given for a clinical reason initially it is no surprise that more patients randomised to the placebo limb of treatment withdraw $[7,8]$. Premature withdrawal is thought to be a weakness in the conduct of these studies but in reality it tells us something of clinical relevance, namely that all things being equal the patients receiving less effective treatment could not continue with the study. As a result of this differential withdrawal the likelihood of finding a difference between the active and comparator groups is reduced, making any estimate of treatment effectiveness a conservative one. This may explain why data on outcomes from database studies such as that by GeRshon et al. [5] are more impressive than the clinical trials data might lead us to expect. However there are downsides to the use of ICS in COPD, with the increased incidence of pneumonia the best-documented treatment risk [9]. This is particularly true for drugs containing the fluticasone moiety [10] where studies involving radiological confirmation of the diagnosis of pneumonia have shown a significantly greater number of events with ICS therapy [11]. These findings are seen in both clinical trials and administrative databases but there is a paradox as the risk of dying is not higher in ICS treated patients as might be expected given the more frequent pneumonic events [12]. This may reflect a change in the character of pneumonias associated with ICS use [13], although more data are needed before this issue can be properly resolved.

Nonetheless there is now more interest in stopping ICS in patients where the risks of pneumonia are high, when the patient has been stable for some time and particularly if the patient has previously had tuberculosis [14]. Early observational studies suggested that simply stopping therapy increased the risk of exacerbations [15]. However more recent data suggest that this may not be true if the patient is receiving

Received: Aug 182015 | Accepted after revision: Aug 292015

Conflict of interest: Disclosures can be found alongside the online version of this article at erj.ersjournals.com

Copyright OERS 2015 
long-acting inhaled bronchodilators, a topic reviewed in detail by SUISSA and Rossi [16] in this issue of the European Respiratory Journal. The uncontrolled observational OPTIMO study found that when the long-acting bronchodilator indacaterol was substituted for ICS in patients where these drugs were not recommended by current treatment guidelines, then the patients did not have an increased risk of exacerbation [17]. The randomised controlled INSTEAD study took this a stage further and found no increased risk of exacerbation in patients without prior exacerbations who had less severe lung function impairment when a once-daily long-acting beta-agonist was used as maintenance therapy [18]. This study has been reviewed in detail previously [19]. Finally the WISDOM study considered an even more challenging patient group who had had previous exacerbations and were given two bronchodilators and ICS therapy before the ICS was randomly withdrawn over 3 months. In this context, continuing with two bronchodilators was as effective as the triple treatment regime [20], although there was a small reduction in forced expiratory volume in $1 \mathrm{~s}\left(\mathrm{FEV}_{1}\right)$ after the ICS was stopped, of a similar magnitude to that seen when patients first receive ICS treatment [4].

SUISSA and Rossi [16] offer a balanced critique of these latter studies and propose a number of areas where study methodology might be improved. Reasonably, they suggest that patients should be receiving ICS for an extended period before entering a withdrawal trial rather than the 6 weeks of intensive therapy used in WISDOM (although $70 \%$ of WISDOM participants were using ICS at study entry). However, as the OPTIMO data illustrate, not all patients have been prescribed treatment for conventional reasons. Thus the population selected should reflect the clinical question. It would be useful to know why ICS treatment was selected initially and then group patients accordingly. Experience with other anti-inflammatory drugs like phosphodiesterase IV inhibitors in COPD has shown that patients with an exacerbation history exacerbate more often, irrespective of their background therapy [21], and that selecting the correct clinical phenotype improves the power of the study to answer its primary question [22]. Simply randomising people by exacerbation history, as SUISSA and Rossi [16] propose, would require a very large study if there was to be sufficient statistical power to adequately test the hypothesis in an unselected population.

Extending the period of follow up will help resolve some of these issues, especially concerns about the risk of more serious exacerbations among patients where ICS are stopped. The similarity between the two limbs of the WISDOM study in terms of risk of subsequent exacerbation make it unlikely that there will a large impact from extending follow-up for moderate exacerbation events. The significance of the small but significant fall in FEV1 after ICS are stopped remains unclear although recent data in abstract form suggest that the loss in lung function is not progressive. Of greater interest would be to define a potentially more ICS-responsive group and see if withdrawal was as trouble-free in that setting. Retrospective analysis of both acute and chronic corticosteroid therapy has suggested that patients with a blood eosinophil count $>2 \%$ respond better to this treatment $[23,24]$ and it will be interesting to see whether the same holds true for ICS withdrawal when a post hoc analysis of the WISDOM data is available.

What does all this mean for the clinician less obsessed by the detail of clinical trial design than participants in the ICS debate? The message here seems relatively straightforward. There is no advantage in adding ICS to bronchodilator therapy in patients at low risk of exacerbations. If the patient has had exacerbations but is clinically stable then ICS can be stopped, provided the patient is using appropriate long-acting inhaled bronchodilator treatment. How rapidly treatment can be withdrawn is still unclear. Perhaps the most important lesson is that we should think a little harder before starting ICS in COPD as it is always harder to stop a treatment once it has begun. Nonetheless these are drugs that can help some patients with COPD and we should be prepared to work harder to define who that group might be.

\section{References}

1 Calverley P, Vlies B. New pharmacotherapeutic approaches for chronic obstructive pulmonary disease. Semin Respir Crit Care Med 2015; 36: 523-542.

2 De Soyza A, Calverley PM. Large trials, new knowledge: the changing face of COPD management. Eur Respir J 2015; 45: 1692-1703.

3 Celli BR, Decramer M, Wedzicha JA, et al. An official American Thoracic Society/European Respiratory Society statement: research questions in COPD. Eur Respir Rev 2015; 24: 159-172.

4 Calverley PM, Anderson JA, Celli B, et al. Salmeterol and fluticasone propionate and survival in chronic obstructive pulmonary disease. N Engl J Med 2007; 356: 775-789.

5 Gershon AS, Campitelli MA, Croxford R, et al. Combination long-acting beta-agonists and inhaled corticosteroids compared with long-acting beta-agonists alone in older adults with chronic obstructive pulmonary disease. JAMA 2014; 312: 1114-1121.

6 Ernst P, Saad N, Suissa S. Inhaled corticosteroids in COPD: the clinical evidence. Eur Respir J 2015; 45: 525-537.

7 Calverley PM, Spencer S, Willits L, et al. Withdrawal from treatment as an outcome in the ISOLDE study of COPD. Chest 2003; 124: 1350-1356.

8 Vestbo J, Anderson JA, Calverley PM, et al. Bias due to withdrawal in long-term randomised trials in COPD: evidence from the TORCH study. Clin Respir J 2011; 5: 44-49. 
9 Crim C, Calverley PM, Anderson JA, et al. Pneumonia risk in COPD patients receiving inhaled corticosteroids alone or in combination: TORCH study results. Eur Respir J 2009; 34: 641-647.

10 Dransfield MT, Bourbeau J, Jones PW, et al. Once-daily inhaled fluticasone furoate and vilanterol versus vilanterol only for prevention of exacerbations of COPD: two replicate double-blind, parallel-group, randomised controlled trials. Lancet Respir Med 2013; 1: 210-223.

11 Crim C, Dransfield MT, Bourbeau J, et al. Pneumonia risk with inhaled fluticasone furoate and vilanterol compared with vilanterol alone in patients with COPD. Ann Am Thorac Soc 2015; 12: 27-34.

12 Festic E, Scanlon PD. Incident pneumonia and mortality in patients with chronic obstructive pulmonary disease. A double effect of inhaled corticosteroids? Am J Respir Crit Care Med 2015; 191: 141-148.

13 Calverley PM, Stockley RA, Seemungal TA, et al. Reported pneumonia in patients with COPD: findings from the INSPIRE study. Chest 2011; 139: 505-512.

14 Dong YH, Chang $\mathrm{CH}$, Lin Wu FL, et al. Use of inhaled corticosteroids in patients with COPD and the risk of TB and influenza: a systematic review and meta-analysis of randomized controlled trials. A systematic review and meta-analysis of randomized controlled trials. Chest 2014; 145: 1286-1297.

15 Jarad NA, Wedzicha JA, Burge PS, et al. An observational study of inhaled corticosteroid withdrawal in stable chronic obstructive pulmonary disease. ISOLDE Study Group. Respir Med 1999; 93: 161-166.

16 Suissa S, Rossi A. Weaning from inhaled corticosteroids in COPD: the evidence. Eur Respir J 2015; 46: 1232-1235.

17 Rossi A, Guerriero M, Corrado A. Withdrawal of inhaled corticosteroids can be safe in COPD patients at low risk of exacerbation: a real-life study on the appropriateness of treatment in moderate COPD patients (OPTIMO). Respir Res 2014; 15: 77.

18 Rossi A, van der Molen T, del Olmo R, et al. INSTEAD: a randomised switch trial of indacaterol versus salmeterol/fluticasone in moderate COPD. Eur Respir J 2014; 44: 1548-1556.

19 Calverley PM. What to use INSTEAD of inhaled corticosteroids in COPD? Eur Respir J 2014; 1391-1393.

20 Magnussen H, Disse B, Rodriguez-Roisin R, et al. Withdrawal of inhaled glucocorticoids and exacerbations of COPD. N Engl J Med 2014; 371: 1285-1294.

21 Bateman ED, Rabe KF, Calverley PM, et al. Roflumilast with long-acting $\beta 2$-agonists for COPD: influence of exacerbation history. Eur Respir J 2011; 38: 553-560.

22 Martinez FJ, Calverley PM, Goehring UM, et al. Effect of roflumilast on exacerbations in patients with severe chronic obstructive pulmonary disease uncontrolled by combination therapy (REACT): a multicentre randomised controlled trial. Lancet 2015; 385: 857-866.

23 Bafadhel M, Davies L, Calverley PM, et al. Blood eosinophil guided prednisolone therapy for exacerbations of COPD: a further analysis. Eur Respir J 2014; 44: 789-791.

24 Pascoe S, Locantore N, Dransfield MT, et al. Blood eosinophil counts, exacerbations, and response to the addition of inhaled fluticasone furoate to vilanterol in patients with chronic obstructive pulmonary disease: a secondary analysis of data from two parallel randomised controlled trials. Lancet Respir Med 2015; 3: 435-442. 